\title{
Can Gastric Specimen Measurements Defines the Laparoscopic Sleeve Gastrectomy Outcome?
}

\author{
Ömer Günal ${ }^{1}$, Kıvılcım Uprak ${ }^{1}$, Muhammer Ergenç ${ }^{1}$, Aylin Erdim²
}

Corresponding author:

Professor Ömer Günal Marmara University Medical Faculty, Department of General Surgery, Pendik Ministry of Health Education and Research Hospital, Turkey E-mail: omergunal@hotmail.com
'Marmara University Medical Faculty, Department of General Surgery, Pendik Ministry of Health Education and Research Hospital, Turkey ${ }^{2}$ Marmara University Health Sciences Faculty, Department of Surgery, Turkey

\section{ABSTRACT}

Background: It is a matter of search that resected gastric specimen measurements (RGSM) has an effect on weight loss following LSG. The aim of this study was to investigate the influence of RGSM on weight loss at 3-6-12 months after LSG.

Methods: 64 Patients who underwent LSG between 2014-2018 at Marmara University Hospital were enrolled. The LSG procedure and RGSMs were performed using standardized techniques. Patients were followed-up every 3 months in the first year. Correlations between the percentages of excess weight losses (EWL) at 3rd, 6th, 12th months and RGSMs were evaluated.

Results: No major complication was seen. Mean body mass index (BMI) at 1 year after LSG was significantly lower than the baseline BMI $50.4 \pm 8.4 \mathrm{~kg} / \mathrm{m}^{2}$ versus $31 \pm 6.1 \mathrm{~kg} / \mathrm{m}^{2}$; $\mathrm{P}=0.001$ ). Mean \% EWLs -3rd, -6th, -12th months were 39\%, 59\%, 75\%, respectively. Resected gastric volume (RGV) was $803.28 \pm 37.2 \mathrm{~mL}$. Expansibility on resection line (LRL-e) was 17.2 $\pm 1.3 \%$. There was no correlation between RGV and \% EWL at 3-6-12 mo. However, the \% EWL-12 mo. was correlated with LRL-e $(r=0,514, p=0,014)$.

Conclusion: There is a positive correlation between 12th mo EWL $\%$ and LRL-e of resected specimen. This may bea harbinger of good weight loss during the theatre.

Key words: laparoscopic sleeve gastrectomy, excess weight loss, gastric expansibility, diamensions

\section{INRODUCTION}

Laparoscopic sleeve gastrectomy (LSG) has still been the most frequently undergone bariatric procedure in TURKEY. The success of weight loss surgery is defined by the rate of excess weight loss (EWL) $(1,2)$. Parameters which affect the excess weight loss percent is the subject of research (3-5). Pawanindra suggested that pre- and post-operative stomach volumes can be important determinants to reveal the effectiveness of LSG (4). Deguines et al. impressed the importance of the resected gastric volume (RGV) in the detection of weight recidivism following LSG (5). Anatomical studies on LSG success defined by 
EWL\% have mostly interested in retained gastric volumes $(5,6)$. These studies used the helical computerized tomograph volumetry that is not seem to be cost effective. We intended to search a more cost effective and useful method of gastric dimension measurement. We therefore investigate a variety of gastric measurements especially the gastric wall expansibility. We have also searched a relationship between this dimensions and excess weight loss percent.

\section{METHODS}

This study was conducted at Marmara University Education and Research Hospital, Istanbul. This study was approved by the institutional review board. We have retrospectively screened the data of our sleeve gastrectomy patients (LSG) who has operated since 2014. A total of 327 obesity surgery patients were screened. 220 patients have undergone sleeve gastrectomy. 64 laparoscopic sleeve gastrectomy patients had gastric specimen measurements. Patients who have gastric specimen measurements were enrolled the study. All patients were followed up according to our clinics follow up algorithm. They were followed up in our outpatient clinic at postoperative $3 \mathrm{rd}$, 6th and 12 th months periods.

In our study we have taken into consideration the anatomic measurements of resected gastric specimen.

\section{Surgery}

We have performed LSG with five trocar technique. Two five $\mathrm{mm}$ (one at subxiphoid for liver Nathanson retractor and one at left anterior axillary line subcostal for assistance), two $15 \mathrm{~mm}$ (one right at subcostal and one at left subcostal midclavicular line), one $10 \mathrm{~mm}$ (at epigastric midline for camera) were inserted to the abdomen.

Following greater curvature preparation from $1 \mathrm{~cm}$ distal to the pylorus to cardio-esophageal junction, an oro-gastric calibration tube of 38 Find welled through the stomach leaning against to lesser curve. Gastric resection accomplished starting upon pylorus and ending over the esophagus without leaving antral and fundal tissue no more than five $\mathrm{mm}$. Gastric resection performed with tampering over the oro-gastric tube by laparoscopic linear cutter. Upon the assumption that the retained gastric tube radius as one $\mathrm{cm}$, our mean gastric tube volume measurement was $86 \mathrm{~cm}^{3}$. (According the mean gastric tube height of $27,3 \mathrm{~cm}$ at
Table 1 - Gastric measurements before insufflation

\begin{tabular}{lcccc}
\hline $\begin{array}{l}\text { Gastric } \\
\text { Measurements }\end{array}$ & $\begin{array}{c}\text { Mean } \\
\text { (cm) }\end{array}$ & $\begin{array}{c}\text { Std. } \\
\text { Dev. }\end{array}$ & Range & $\begin{array}{c}\text { Median } \\
\text { (cm) }\end{array}$ \\
\hline LRL & 23.5 & 3.9 & $15-34$ & 23 \\
\hline LGC & 37 & 5.1 & $26-56$ & 37.7 \\
\hline WF & 5.8 & 1 & $2-8$ & 6 \\
\hline WA & 4.7 & 0.7 & $3-6.5$ & 4,8 \\
\hline TF & 1.2 & 0.3 & $0,8-2.5$ & 1.2 \\
\hline TA & 1.2 & 03 & $0.5-2$ & 1.05 \\
\hline
\end{tabular}

LRL - Length of Resection Line, LGC - Length of Greater Curvature, WF - Width of Fundus, WA - Width of Antrum,

TF - Thickness of Fundus and TA - Thickness of Antrum

table 1) Resected gastric specimen was taken out the abdomen through the upper left trocar hole without compromising its anatomic integrity.

\section{Anatomic measurements}

The lengths of stapler (resection site) line (LRL), greater curvature (LGC), width of fundus (WF) and antrum (WA), tissue thickness (double-wall thicknesses) of fundus (TF) and antrum (TA) were all measured before and after the gastric specimen insufflation with $\mathrm{CO} 2$ through the hole at the pyloric site of the stomach (fig. 1). The $\mathrm{CO} 2$ volume insufflated by 10 $\mathrm{mmHg}$ assumed as the gastric volume. The difference

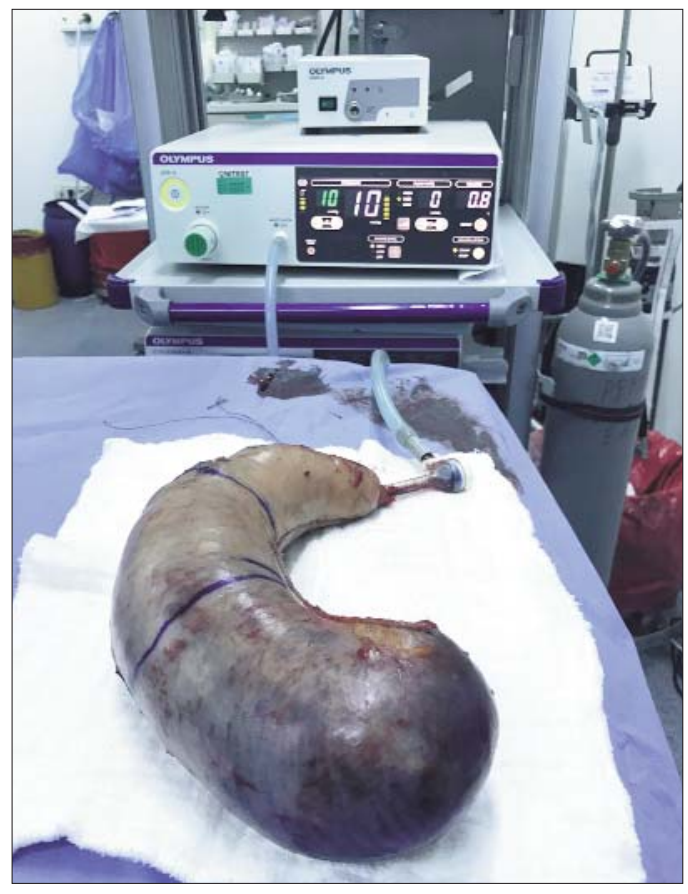

Figure 1 - Gastric specimen insufflation setting 
between the measurements before and after specimen insufflation as a percentage were assumed as expansion rates (table 1). The relationship between gastric measurements-expansion rates and EWL percents at postoperative third, sixth and twelfth months was investigated. The correlation between the 3rd, 6th, 12th months EWL\% and gastric volume, LRL, LGC, WF, WA, TF, TA expansion rates were also analyzed with correlation analysis.

\section{Calculation of resected gastric measurements expansion rate (RGM-e)}

Assumed as the rate of difference between pre and post insufflation measurement value to pre insufflation measurement value of each gastric dimension.

EXAMPLE: Length of Resection Line Expansion rate (LRL-e) $L R L-e=($ pi $L R L-p o i ~ L R L) /(p i ~ L R L)$

pi: preinsufflation

poi: postinsufflation

Expansion rate was assumed as an indicator of elasticity.

\section{Statistical analysis}

The results were presented as mean \pm s.d. and median (range). Comparison between continuous variables were done with student's $t$ test. Non-parametric variables were compared with Mann Whitney $U$ test. Correlation between groups searched with Pearson's correlation test. If $p$ value was less than 0,05 it was considered significant. Factors which were thought to have an effect on EWL\% underwent a regression analysis. If $p<0,05$ it was considered significant.

\section{RESULTS}

Male/Female ratio was $15 / 49$. The mean age was 41.5 \pm 1.4 years (range, 21-62 yr). Third, sixth and twelve month EWL percents were $39.4 \pm 1.5 \%, 59.2 \pm 2 \%$, $74.6 \pm 3 \%$ respectively.Body mass indexes (BMI) were $40,8 \pm 1,36,2 \pm, 31 \pm 1 \mathrm{~kg} / \mathrm{m}^{2}$ at the same time intervals. Male/Female mean gastric specimen volumes (GSV) were $970 \pm 91.5 \mathrm{ml} / 748.9 \pm 36.5 \mathrm{ml} .(p=0.0001)$. The overall group mean GSV was $803.28 \pm 37.2 \mathrm{ml}$. The mean LRL, LGC, WF and WA, TF and TA expansion rates were $17.2 \pm 1.3 \%, 35 \pm 2.2 \%, 110,3 \pm 6.9 \%, 80.9 \pm 3.7 \%$, $493.4 \pm 21.2 \%$ and $330.6 \pm 15.9 \%$ respectively. We have found a correlation between the 12th month EWL \%
Table 2 - Gastric measurements after insufflation

\begin{tabular}{lcccc}
\hline $\begin{array}{l}\text { Gastric } \\
\text { Measurements }\end{array}$ & $\begin{array}{c}\text { Mean } \\
(\mathrm{cm})\end{array}$ & Std. Dev. & Range & $\begin{array}{c}\text { Median } \\
(\mathrm{cm})\end{array}$ \\
\hline LRL & 27.3 & 3.8 & $17-37$ & 27 \\
\hline LGC & 51.4 & 9.5 & $32-84$ & 51 \\
\hline WF & 11.8 & 2.2 & $6.5-19$ & 12 \\
\hdashline WA & 8.5 & 1.6 & $4.5-11$ & 9 \\
\hdashline TF & 7.1 & 1.6 & $3.5-12$ & 7 \\
\hline TA & 4.9 & 1.2 & $2-9$ & 3.5 \\
\hline
\end{tabular}

LRL - Length of Resection Line, LGC; Length of Greater Curvature, WF - Width of Fundus, WA - Width of Antrum,

TF - Thickness of Fundus and TA - Thickness of Antrum

and LRL expansion rates (Spearman's correlation coefficient $r=0.504, p=0,014$ ).

Pre- and post-insufflation gastric measurement values were presented in table 1 and 2. All the gastric dimensions have a two to five fold increase after insufflation. All these parameters pre and postinsufflation values underwent Pearson's correlation analysis with the 3rd, 6th, 12th mo. EWL\%. Only WF and WA has the correlation with EWL\% on 6th and 12th months respectively. However on regression analysis they have not significant effect on EWL\% $(p<0,05)$.

Gastric Wall expansion rates were presented in table 3. Thickness of fundus and thickness of antrum measurers were showing the most significant increments as expansibility. The ralationship between the gastric dimensions expansibility and EWL at different time points is presented at table 4 . We have found only one positive correlation between resection line expansibility (LRL-e) and 12th month EWL\%. When we have performed a regression analysis to see the effects of factors that have correlation with EWL\%, we have found the age as an only effective on 6th month EWL\%.

\section{DISCUSSION}

Success rate following LSG is one of the topic of research due to the weight regain rates approaching to $20 \%$ during 5 years follow up periods (1). However, EWL\% still stay above $50 \%$ after 5 year followup (3). In long term follow period, predicting such patients before treatment failure may enable the surgeon to take precautions for preventing recurrences. This approach also provide savings in health expenditures and labor economy.

The mechanisms of weight loss after LSG are multifactorial; a combination of gastric restriction, hormonal factors, and changes in gastric emptying and 
Table 3 - Gastric expansion rates and 3rd., 6th., 12th mo.EWL\%s

\begin{tabular}{|c|c|c|c|c|}
\hline $\begin{array}{l}\text { Specimen Measurement } \\
\text { Type }\end{array}$ & $\begin{array}{c}\text { Measurement } \\
(\text { mean } \pm s d)\end{array}$ & $\begin{array}{c}\text { 3rd Mo.Excess } \\
\text { Weight Loss Percent }\end{array}$ & $\begin{array}{c}\text { 6th Mo. Excess } \\
\text { Weight Loss Percent }\end{array}$ & $\begin{array}{l}\text { 12th Mo. Excess } \\
\text { Weight Loss Percent }\end{array}$ \\
\hline LRL-e & $17.2 \pm 1.3 \%$ & $39.4 \pm 1.5 \%$ & $59.2 \pm 2 \%$ & $74.6 \pm 3 \%$ \\
\hline LGC-e & $35 \pm 2.2 \%$ & “ & "“ & \\
\hline WF-e & $110,3 \pm 6.9 \%$ & $“$ & " " & \\
\hline WA-e & $80.9 \pm 3.7 \%$ & $"$ & "“ & \\
\hline TF-e & $493.4 \pm 21.2 \%$ & “ & "“ & \\
\hline TA-e & $330.6 \pm 15.9 \%$ & $“$ & "“ & \\
\hline SAV-e & $803.28 \pm 37.2$ & “ & " “ & \\
\hline
\end{tabular}

LRL - Length of Resection Line, LGC - Length of Greater Curvature, WF - Width of Fundus, WA - Width of Antrum, TF - Thickness of Fundus and TA - Thickness of Antrum, SAR - Specimen Air Volume. -e - expansibility

Table 4 - Correlation analysis between subgroups and EWL\%

\begin{tabular}{|c|c|c|c|c|}
\hline $\begin{array}{l}\text { Specimen Measurement } \\
\text { Type }\end{array}$ & $\begin{array}{l}\text { Measurement } \\
\text { (mean } \pm s d)\end{array}$ & $\begin{array}{c}\text { Correlation Between } \\
\text { 3rd Mo.Excess Weight } \\
\text { Loss Percent }\end{array}$ & $\begin{array}{c}\text { Correlation Between } \\
\text { 6th Mo. Excess Weight } \\
\text { Loss Percent }\end{array}$ & $\begin{array}{c}\text { Correlation Between } \\
\text { 12th Mo. Excess Weight } \\
\text { Loss Percent }\end{array}$ \\
\hline LRL-e & $17.2 \pm 1.3 \%$ & $r=-0.319 \quad p=0.148$ & $r=0.259 \quad p=0.111$ & $r=0.514 \quad p=0.014$ \\
\hline LGC-e & $35 \pm 2.2 \%$ & $r=-0.051 p=0.709 p=$ & $r=-0.201 \quad p=0.208$ & $r=-0.319 \quad p=0.148$ \\
\hline WF-e & $110.3 \pm 6.9 \%$ & $r=-0.081 \quad p=0.562$ & $r=-0.055 \quad p=0.740$ & $r=0.174 \quad p=0.438$ \\
\hline WA-e & $80.9 \pm 3.7 \%$ & $r=0.148 \quad p=0.282$ & $r=-0.017 \quad p=0.917$ & $r=-0.046 \quad p=0.837$ \\
\hline TF-e & $493.4 \pm 21.2 \%$ & $r=0.143 \quad p=0.287$ & $r=0.231 \quad p=0.147$ & $r=0.038 \quad p=0.864$ \\
\hline TA-e & $330.6 \pm 15.9 \%$ & $r=0.061 \quad p=0.652$ & $r=-0.025 \quad p=0.878$ & $r=0.183 \quad p=0.403$ \\
\hline SAV (ml) & $803.28 \pm 37.2$ & $r=-0.202 \quad p=0.143$ & $r=-0.280 \quad p=0.084$ & $R=-0.302 \quad p=0.061$ \\
\hline
\end{tabular}

LRL - Length of Resection Line. LGC - Length of Greater Curvature. WF - Width of Fundus. WA - Width of Antrum. TF - Thickness of Fundus and TA - Thickness of Antrum. SAR - Specimen Air Volume. -e - Expansibility percent

eating habits are involved (2). However, the degree of restriction performed plays the most important role (7). This restriction level directly related to the retained gastric volume, indirectly to the specimen volume or dimensions.

Rates of regain ranged from $5.7 \%$ at 2 years to $75.6 \%$ at 6 years. LSG has $10-20 \%$ reoperative surgery rate due to weight regain or inadequate weight loss $(1,5,8-10)$. Most frequent reason of weight regain following LSG is the gastric pouch enlargement. Gastric pouch enlargement may be related to the elasticity of the gastric wall. Increased stomach wall elasticity, thus the receptive relaxation of the gastric pouch wall would be able to responsible for the pouch enlargement after such a big amount food intake. That is why we intended to calculate the gastric elasticity by measuring the resected gastric specimen before and after insufflation (4). An adaptive relaxation of the gastric wall following oral intake may prevent it from in appropriately dilatation.

Our study is unique in the literature with its evaluation of gastric specimen expansibility. In our series, mean gastric specimen volume was $803.28 \pm 37.2 \mathrm{ml}$. convenient with literature. Male resected specimen volumes are more than the female ones $(970 \pm 91.5 \mathrm{ml} /$ $748.9 \pm 36.5 \mathrm{ml}$ respectively). Although we have found a significant correlation between resection line expansibility and 12th mo EWL\%, that is not seem to be so, on regression analysis (table 5). EWL\% and BMIs at 3rd, 6th and 12th month intervals seem to be more than the literature figures $(11,12)$.

We have encountered a number of studies that were evaluating the gastric specimen measurements $(2,4,5,13)$. Most of the studies in the literature have taken into consideration that the gastric specimen volume as an independent factor affecting the EWL\% (4-6). However, in our study we have concerned the gastric wall elasticity thus receptive capacity. Together with this we have also taken six more gastric measurements (table 1 and 2). Another point concerning gastric measurement is that most of the studies regarded the residuel gastric volume (RGV) as a measure. Some of them could not find any relationship between the EWL\% and RGV (14). Hanssen et al 
Table 5 - Factor affecting EWL\% (Lineer Regression analysis)

\begin{tabular}{lcccccc}
\hline Parameters & $\begin{array}{c}\text { 3rd Mo.EWL\% } \\
\text { Confidence interval }\end{array}$ & $\mathbf{p}$ & $\begin{array}{c}\text { 6th Mo.EWL\% } \\
\text { Confidence interval }\end{array}$ & $\mathbf{p}$ & $\begin{array}{c}\text { 12th Mo.EWL\% } \\
\text { Confidence interval }\end{array}$ & $\mathbf{p}$ \\
\hline LRL-e (\%) & $-0.215-0.211$ & 0.983 & $-0.09-1.3$ & 0.08 & $0.2-2.19$ & 0.18 \\
\hline WF & $-4.140-4.174$ & 0.993 & $-8-6$ & 0.78 & $-15-13.4$ & 0.9 \\
\hline WA & $-5.345-7.021$ & 0.787 & $-8-8$ & 0.945 & $-15-19$ & 0.8 \\
\hdashline Age & $-0.505-0.167$ & 0.317 & $-1.13-0.05$ & 0.033 & $-1.3-0.8$ & 0.639 \\
\hline
\end{tabular}

LRL - Length of Resection Line expansibility. WF - Width of Fundus. WA - Width of Antrum

found out a negative correlation between RGV and 6th month EWL\% (6). They have figured out that patients who have more than $100 \mathrm{ml}$ gastric pouch volume at 6th month after LSG are associated with poor EWL.

However Deguines et al. suggests "redo surgery" when RGV exceed over $250 \mathrm{ml}$. They offer their patients repeat $L S G$ (RLSG). Limited number of studies tried to read what the excised stomach told us. As an early indicator of weight recidivism, resected gastric specimen measurements may be a helpful tool. Fahmy MHA et al. proposed gastric computerized tomography volumetry (GCTV) for residual gastric volume measurement for the early detection of weight recidivism $(4,15)$. However, they could only recognize weight recidivism as early as one and half 2 years. We intended to detect weight recidivism as early as in the theatre by measuring RGMs concerning postoperative $3 \mathrm{rd}$, 6th or 12 th months. All these studies showed the RGV by using gastric computed tomography volumetry (GCTV). With respect to cost effectiveness and radiation exposure GCTV seems to be non-practical for routine use.

Pawanindra et al have proposed that early postoperative weight loss ( 3 months) correlates well with the volume of the excised stomach but not with that of the gastric sleeve (4). We have observed nearly a two to five fold increase in gastric specimen's sizes following insufflation. We have also found a positive correlation between 12th mo EWL\% and LRL-e value (table 4). This correlation may be interpreted as the good receptive relaxation response in stapler line. That would protect the gastric pouch from uncontrolled dilatation. However this hypothesis need to be proven $(14,16)$.

The effects of the volume and weight of the resected stomach were studied previously (17). There are different results about the relationship between resected gastric volume and weight loss. In addition, gastric flexibility was examined and no direct associa- tion with excess weight loss (\% EWL) was shown (18). Our method seems to be precautioning the surgeon as early as in the theatre that patient who have increased LRL-e will have good EWL at least post-operative $12 \mathrm{mo}$. However, limitations of our study, such as less patient number and short follow up period necessitates to overcome these drawbacks. Although the antrum width (WA) and fundus width (WF) (before insufflation) has not been seemed to affect the 6th month EWL\% on regression analysis (table 5), we had found a correlation between them and EWL\% in sub group analysis $(p<0,05)$.

There is a positive correlation between 12th mo EWL\% and LRL-e of resected specimen. This figure holds promise as a harbinger of good weight loss that cautioning surgeon immediately in the theatre. There withal, WF and WA values can also be considered as an harbingers of EWL\% at the future prospective trials.

\section{Conflicts of interest}

There is no conflict of interest.

\section{REFERENCES}

1. Weiner RA, Theodoridou S, Weiner S.Failure of laparoscopic sleeve gastrectomy- further procedure? Obes Facts. 2011;4 Suppl 1:42-46.

2. Obeidat F, Shanti H, Mismar A, Albsoul N, Al-Qudah M. The Magnitude of Antral Resection in Laparoscopic Sleeve Gastrectomy and its Relationship to Excess Weight Loss. Obes Surg. 2015; 25(10):1928-1932.

3. Diamantis T, Apostolou KG, Alexandrou A, Griniatsos J, Felekouras $\mathrm{E}$, Tsigris $\mathrm{C}$. Review of long-term weight loss results after laparoscopic sleeve gastrectomy. Surg Obes Relat Dis. 2014; 10(1):177-183.

4. Pawanindra L, Vindal A, Midha M, Nagpal P, Manchanda A, Chander J. Early post-operative weight loss after laparoscopic sleeve gastrectomy correlates with the volume of the excised stomach and not with that of the sleeve! Preliminary data from a multi-detector computed tomography-based study. Surg Endosc; 2015, 29(10): 2921-2927.

5. Deguines JB, Verhaeghe P, Yzet T, Robert B, Cosse C, Regimbeau JM. Is the residual gastric volume after laparoscopic sleeve gastrectomy an objective criterion for adapting the treatment strategy after failure? Surg Obes Relat Dis. 2013;9(5):660-666.

6. Hanssen A, Plotnikov S, Acosta G, Nunez JT, Haddad J, Rodriguez 
C, et al. 3D Volumetry and its Correlation Between Postoperative Gastric Volume and Excess Weight Loss After Sleeve Gastrectomy. Obes Surg. 2018;28(3):775-780.

7. Papailiou J, Albanopoulos K, Toutouzas KG, Tsigris C, Nikiteas N, Zografos G. Morbid obesity and sleeve gastrectomy: how does it work? Obes Surg. 2010;20(10):1448-1455

8. Lauti M, Kularatna M, Hill AG, MacCormick AD. Weight Regain Following Sleeve Gastrectomy-a Systematic Review. Obes Surg. 2016; 26(6):1326-1334.

9. Braghetto I, Korn O, Valladares $H$, Gutierrez L, Csendes A, Debandi $A$, et al. Laparoscopic sleeve gastrectomy: surgical technique, indications and clinical results. Obes Surg. 2007:17(11):1442-1450

10. Iannelli A, Schneck AS, Dahman M, Negri C, Gugenheim J. Two-step laparoscopic duodenal switch for superobesity: a feasibility study. Surg Endosc. 2009;23(10):2385-2389.

11. Bellanger DE, Greenway FL. Laparoscopic sleeve gastrectomy, 529 cases without a leak: short-term results and technical considerations. Obes Surg. 2011;21(2):146-150.

12. Salman Yousuf Guraya KRM. Laparoscopic sleeve gastrectomy for morbid obesity: the future of bariatric surgery? British Journal of Medicine \& Medical Research. 2011;1(4):212-222.
13. Barbiero G, Romanucci G, Ortu V, Zuliani M, Miotto D, Pomerri F, et al. Relationship between gastric pouch and weight loss after laparoscopic sleeve gastrectomy. Surg Endosc. 2016;30(4):1559-1563.

14. Du X, Luo R, Chen YY, Peng BQ, Hu JK, Cheng Z. Resected gastric volume has no influence on early weight loss after laparoscopic sleeve gastrectomy. Surg Obes Relat Dis. 2018;14(2):129-135.

15. Fahmy MH, Sarhan MD, Osman AM, Badran A, Ayad A, Serour DK, et al. Early weight recidivism following laparoscopic sleeve gastrectomy: a prospective observational study. Obes Surg. 2016; 26(11): 2654-2660.

16. Ferrer-Marquez M, Garcia-Diaz JJ, Moreno-Serrano A, Garcia-Diez $\mathrm{JM}$, Ferrer-Ayza M, Alarcon-Rodriguez R, et al. Changes in gastric volume and their implications for weight loss after laparoscopic sleeve gastrectomy. Obes Surg. 2017;27(2):303-309.

17. Bekheit M, Abdel-Baki TN, Gamal M, Abdel-Salam W, Samir M, EIKayal E, et al. Influence of the Resected Gastric Volume on the Weight Loss After Laparoscopic Sleeve Gastrectomy. Obes Surg.2016;26(7):1505-1510.

18. Toro JP, Patel AD, Lytle NW, Perez S, Edward L, Singh A, et al. Observed Variability in Sleeve Gastrectomy Volume and Compliance Does Not Correlate to Postoperative Outcomes. Surg Laparosc Endosc Percutan Tech.2015;25(4):324-330. 